\title{
Walker, Chair of the House Committee on Science, to Give Plenary Talk
}

The plenary presentation at the Materials Research Society's 1995 Fall Meeting in Boston will be given by U.S. Representative Robert S. Walker, chair of the House Committee on Science. The Plenary Session is scheduled for Monday, November 27, at 6 p.m., in Salon E at the Boston Marriott.

As chair of the 50-member committee, whose jurisdiction includes space and aeronautics, basic research, energy and environment research and development, and technology, Walker will address the status of U.S. science policy. His talk will be followed on Tuesday morning by a forum on the Changing Character of Science Policy.

Walker is also vice chair of the Committee on Budget and chair of the Republican Leadership group. He is a member of the Republican Steering Committee which

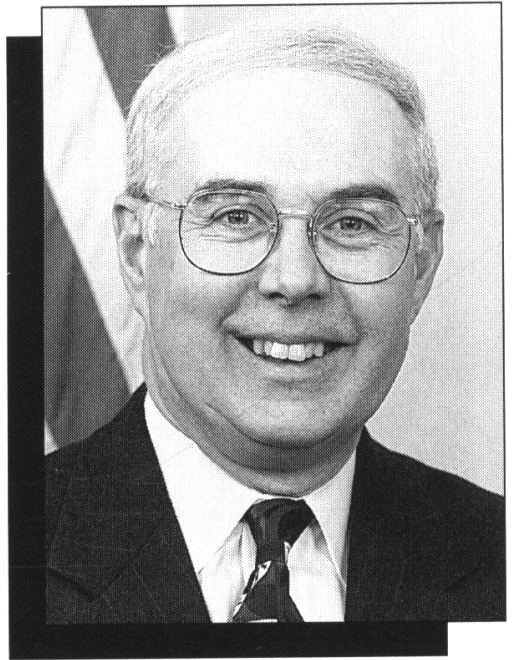

assigns members to committees and steers the legislative agenda. Among his legislative focuses have been the Omnibus Space Commercialization Act and advocacy of research and development of hydrogen as an alternative fuel source.

Before starting his career in the U.S. House of Representatives in 1977, Walker worked as a congressional assistant to U.S. Representative Edwin Eshleman from 1967-1977. Walker received his BS degree in education from Millersville University in 1964 and his Master's degree in political science from the University of Delaware in 1968. While studying for his Master's degree, Walker served on the Pennsylvania National Guard (1967-1973). He is the author or co-author of several books and articles, including Space, Our Next Frontier published in 1985.

\section{Our New CVD Copper (I) Source Isn't Just an Alternative Source It Is a More Practical One For Production}

While maintaining all the characteristics that CVD Cu process requires, the new CVD Cu(I) source addresses one critical issue: thermal stability. This new $\mathrm{Cu}$ precursor is an extremely stable source material and provides long shelflife.

Chemat Technology specializes in metal-organic precursors for CVD. Our products include the precursors for:

Nitride: TiN, TaN, AlN, GaN, $\mathrm{ZrN}$ and more.

Oxide: $\mathrm{Ta}_{2} \mathrm{O}_{5}, \mathrm{Nb}_{2} \mathrm{O}_{5}, \mathrm{ZrO}_{2}, \mathrm{BST}, \mathrm{PZT}$ and more.

Chemat also developed air-stable, single source,

polymeric precursors for spin-on process: $\mathrm{BST}, \mathrm{PZT}$,

PLLT, ATO, and ITO

Quality and Service: Our technical staff will work with you to find the right chemicals for your applications. We will meet your purity requirements. For liquid precursors, we provide the bubblers which can be connected to your system.

To find out more, call $\mathbf{1 - 8 0 0 - 4 7 5 - 3 6 2 8}$

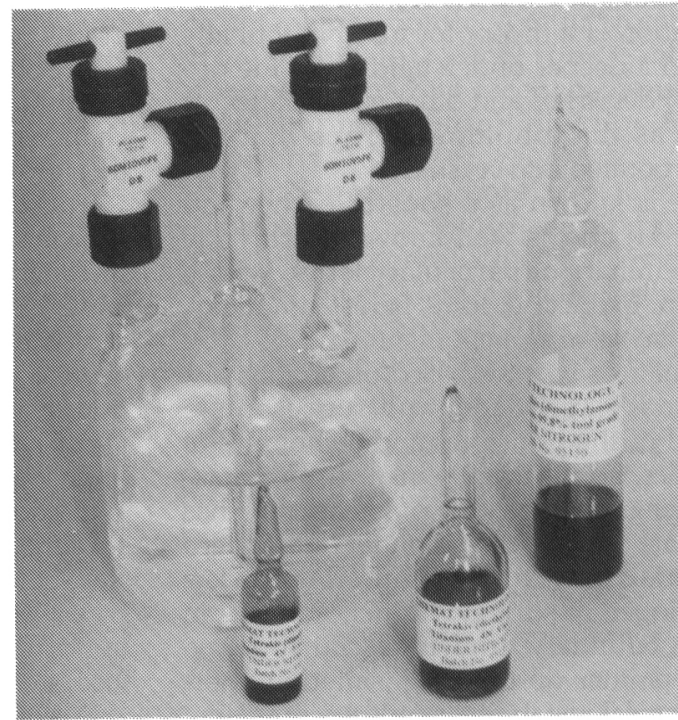

CHEMAT TECHNOLOGY, INC.
19365 Business Center Dr., \#9

Northridge, CA 91324

(818)727-9477 (Fax)

Circle No. 12 on Reader Service Card. 